\title{
AVALIAÇÃO DO POTENCIAL TÓXICO REPRODUTIVO DO EXTRATO DO FRUTO DE Buchenavia sp EM RATOS MACHOS IMPÚBERES DA LINHAGEM WISTAR
}

(Reproductive toxic potential of the evaluation of the Buchenavia sp fruit extract in prepurbetal Wistar rats)

Marcos Daniel de Sousa Ferreira ${ }^{1}$, Emanuela Ribeiro Moura, Emanuelle Karine Frota Batista, Silvana Maria Medeiros de Sousa Silva, Francisco das Chagas Cardoso Filho, Maria do Carmo de Souza Batista

${ }^{1}$ Correspondência: marcos_daniel_pi@hotmail.com

RESUMO: O objetivo deste trabalho foi avaliar os possíveis efeitos tóxicos do extrato aquoso do fruto de Buchenavia sp. sobre o sistema reprodutivo de ratos impúberes, pesquisando as atividades androgênica e antiandrogênica e sinais de toxicidade sistêmica. Foi empregado o protocolo de curta duração (Teste de Hershberger). Foram utilizados 64 ratos impúberes, divididos em oito grupos de oito animais: controle positivo, controle negativo, extrato $250 \mathrm{mg} / 100 \mathrm{~g}$, extrato $500 \mathrm{mg} / 100 \mathrm{~g}$, extrato $1000 \mathrm{mg} / 100 \mathrm{~g}$, extrato $250 \mathrm{mg} / 100 \mathrm{~g}$ + testosterona, extrato $500 \mathrm{mg} / 100 \mathrm{~g}+$ testosterona, extrato $1000 \mathrm{mg} / 100 \mathrm{~g}$ + testosterona, Os resultados mostram que durante o período de realização dos tratamentos, o extrato aquoso do fruto da Buchenavia sp não apresentou atividade androgênica ou antiandrogênica em ratos impúberes segundo o protocolo de curta duração, bem como, não influenciou no ganho de peso dos animais e não levou a observação de alterações degenerativas, inflamatórias ou necróticas dos órgãos analisados e não desencadeou toxicidade sistêmica.

Palavras-chave: mirindiba; planta tóxica; ratos; toxicidade reprodutiva

ABSTRACT: The objective of this study was to evaluate the possible toxic effects of the aqueous extract of the fruit of Buchenavia sp. on the reproductive system of prepubertal rats, researching the androgenic and anti-androgenic activity and systemic signs of toxicity. . We used the short protocol (Hershberger Test), 64 rats prepubertal were divided into eight groups of eight animals: positive control, negative control, $250 \mathrm{mg} / 100 \mathrm{~g}$ extract, $500 \mathrm{mg} / 100 \mathrm{~g}$ extract, extract $1000 \mathrm{mg} / 100 \mathrm{~g}$, extract $250 \mathrm{mg} / 100 \mathrm{~g}$ + testosterone extract $500 \mathrm{mg} / 100 \mathrm{~g}$ + testosterone, $1000 \mathrm{mg} / 100 \mathrm{~g}+$ testosterone extract,. The results show that during the period of completion of treatment, the aqueous extract of the Buchenavia sp fruit showed no androgenic or anti-androgenic activity in prepubertal rats according to the short protocol and had no influence on the animals' weight gain and did not take observation of degenerative, inflammatory or necrotic changes of the organs analyzed and did not elicit systemic toxicity.

Key Words: mirindiba; plant toxic; rats; reproductive toxicity 


\section{INTRODUÇÃO}

O uso de plantas medicinais pela população tem sido muito significativo nos últimos tempos. A realização de estudos evita o uso indiscriminado de plantas com efeitos adversos e estimula a utilização correta das plantas, o que os torna de fundamental importância para provar a sua segurança (BRANDOLT, 2007).

As plantas do Cerrado são fontes de alimentos e medicamentos para a população que vive nesta região. O gênero Buchenavia (Reino: Plantae; Divisão: Magnoliophyta; Classe: Magnoliopsida; Ordem: Myrtales; Família: Combretaceae) com cerca de 25 espécies, está distribuído na América Tropical, desde a América Central, em Cuba, Trinidad, Panamá, Índias Ocidentais, até Venezuela, Colômbia, Guianas, Brasil, Peru e Bolívia. Na região amazônica, há a maior concentração de espécies, vinte ao todo na região, no sudeste do Brasil ocorrem seis e uma atinge a região sul. $O$ gênero é caracterizado por porte arbustivo, de folhas alternas, aglomeradas no ápice. Os frutos são drupóides, arredondados e sementes apresentam cotilédones convolutos. A Buchenavia tomentosa popularmente chamada de mirindiba ou birindiba é uma planta muito comum nas regiões amazônica e nordestina. No Brasil, os frutos desta planta são utilizadas na alimentação humana e medicina popular (MARQUETE; VALENTE, 2005; MELLO et al., 2010; POTT; POTT,1986; POTT et al., 2006).

Os frutos de Buchenavia tomentosa são consumidos frescos, como suco ou doce e na medicina popular é usado contra tosse. O gado consome abundantemente seus frutos, folhas e desfruta de sombra dessa planta, que é indicada para consórcio em pastagens. Um levantamento sobre as plantas tóxicas para ruminantes e eqüídeos realizado na Mesorregião Norte do Piauí relatou plantas como tóxicas pelos entrevistados, mas sem que haja comprovação de sua toxicidade. Nesse levantamento a Buchenavia tomentosa foi relatada como uma planta tóxica por produtores, pois, de acordo com os entrevistados, os frutos de Buchenavia tomentosa causariam alterações digestivas e abortos em caprinos, ovinos e bovinos (MELLO et al., 2010).

Há relatos de criadores de gado do Tocantins e do Piauí de que a ingestão de frutos da planta estaria, de alguma forma, associada à ocorrência de abortos, diarreia, fraqueza, perda de peso, nascimento de animais fracos e até a morte de animais (COSTA, 2009; MELLO et al., 2010).

Estudo realizado por Ferreira et al., (2016) mostrou que o extrato etanólico da casca do caule de Buchenavia sp., desencadeia leves sinais de intoxicação sistêmica, mas não interfere significativamente no processo de reprodução da fêmea, fato que denota a necessidade de se averiguar o seu efeito sobre o processo reprodutivo de machos para que se tenha uma resposta definitiva sobre a sua influência na reprodução.

A existência de atividade androgênica em plantas pode representar além de possíveis novas indicações terapêuticas, efeitos colaterais indesejáveis sobre a reprodução, principalmente inibição da espermatogênese no macho e masculinização de fêmeas. Assim, de acordo com o enfoque, a comprovação dessas atividades pode representar uma indicação terapêutica ou indicar um efeito adverso.

A avaliação de atividade androgênica e anti-androgênica pode ser feita administrando-se o extrato do vegetal em ratos ou camundongos, castrados ou impúberes. As glândulas sexuais acessórias são muito sensíveis ao andrógeno, aumentando de volume quando expostas a pequenas doses. Os 
andrógenos também são capazes de inibir a espermatogênese quando aplicados em animais não castrados por um período longo, devido ao efeito inibitório sobre a secreção de Hormônio Folículo- Estimulante (FSH). Em muitas plantas já foram encontrados constituintes anti-androgênicos, como os flavonóides de Dalbergia conchichinensis (ABOU-DONIA, 1998), e preniflavanóides de Sophora flavescens (KUROYANGI et al, 1999).

Nesse contexto, este trabalho foi realizado com o objetivo avaliar possíveis efeitos do extrato aquoso do fruto de Buchenavia sp. sobre o sistema reprodutivo de ratos machos impúberes da linhagem Wistar, pesquisando as atividades androgênica e antiandrogênica, e sinais de toxicidade sistêmica, como forma de contribuir para o estudo farmacológico da espécie, de forma a subsidiar investigações científicas que possam ser úteis no domínio da toxicologia.

\section{MATERIAL E MÉTODOS}

Os experimentos foram conduzidos no Laboratório de Ciências Fisiológicas do Departamento de Morfofisiologia Veterinária (DMV) do Centro de Ciências Agrárias (CCA) da Universidade Federal do Piauí.

Foram utilizados ratos Wistar impúberes, criados e mantidos no Biotério de Manutenção de Animais de Experimentação (BIOMADEX) do CCA da UFPI. Os animais foram mantidos em regime de 12 horas de luz e 12 horas de escuridão, em sala com ar condicionado e livre acesso a água e ração (FRI-LAB Ratos - Fri-Ribe®).

\section{Material Vegetal e Preparo do Extrato:}

Foram coletados cerca de $35 \mathrm{Kg}$ de frutos da Buchenavia sp. no município de Campo Maior estado do Piauí, no período de frutificação e mantidas sob refrigeração até 0 momento do preparo do extrato. As frutas (aproximadamente $10 \mathrm{~kg}$ ) foram descongeladas em temperatura ambiente e processados em liquidificador doméstico posteriormente filtrado e a massa restante separada do caroço e colocado em uma estufa de circulação de ar (mantido a $45^{\circ} \mathrm{C}$ ) por 15 dias até perder completamente sua fração aquosa. Em seguida, o material resultante (seco) foi triturado em um moinho mecânico e o pó obtido foi misturado a parte líquida obtida inicialmente. Nesta fase, a homogeneização ocorreu de forma contínua até todo o liquido resultante ser separado em volumes menores para facilitar o armazenamento. Foram recolhidas 3 alíquotas de $1 \mathrm{~mL}$ da solução e colocadas em frascos previamente autoclavados, identificados e pesados em balança de precisão para a verificação do peso seco. As alíquotas foram mantidas em estufa a $45^{\circ} \mathrm{C}$ até que a fração aquosa evaporasse completamente, para isso, os recipientes permaneceram em estufa por oito dias e passaram a ser pesados em balança de precisão uma vez ao dia até que o peso final ficasse estabilizado por dois dias consecutivos chegando-se a concentração final do extrato no valor de $0,339 \mathrm{mg} / \mathrm{mL}$.

\section{Pesquisa da atividade androgênica e anti-androgênica}

Foram utilizados 64 ratos impúberes, divididos em oito grupos de oito animais cada, assim distribuídos:

Controle positivo: os animais receberam solução de testosterona na concentração de $5 \mathrm{mg} / \mathrm{mL}$, no volume de $0,1 \mathrm{~mL} / 100 \mathrm{~g}$ de peso corporal por via subcutânea (Sc) e solução salina a $0,9 \%$, por via oral (vo), no volume de 1 $\mathrm{mL} / 100 \mathrm{~g}$, por gavagem; 
Controle negativo: os animais receberam Solução salina a $0,9 \%$, por gavagem, no volume de $1 \mathrm{~mL} / 100 \mathrm{~g}$.

Extrato 250mg/100g: os animais receberam extrato, na concentração de $250 \mathrm{mg} / \mathrm{mL}$, no volume de $1 \mathrm{~mL} / 100 \mathrm{~g}$ de peso corporal, por gavagem.

Extrato 500mg/100g: os animais receberam extrato na concentração de $500 \mathrm{mg} / \mathrm{mL}$, no volume de $1 \mathrm{~mL} / 100 \mathrm{~g}$ de peso corporal, por gavagem.

Extrato $1000 \mathrm{mg} / 100 \mathrm{~g}$ : os animais receberam extrato na concentração de $1000 \mathrm{mg} / \mathrm{mL}$, no volume de $1 \mathrm{~mL} / 100 \mathrm{~g}$ de peso corporal, por gavagem.

Extrato $250 \mathrm{mg} / \mathbf{1 0 0 g}$ + Testosterona: os animais receberam solução de testosterona na concentração de $5 \mathrm{mg} / \mathrm{ml}$, volume de $0,1 \mathrm{~mL} / 100 \mathrm{~g}$ de peso corporal por via subcutânea e extrato na concentração de $250 \mathrm{mg} / \mathrm{ml}$ no volume de $1 \mathrm{ml} / 100 \mathrm{~g}$ de peso corporal por gavagem.

Extrato $500 \mathrm{mg} / \mathbf{1 0 0 \mathrm { g }}$ + Testosterona: os animais receberam solução de testosterona na concentração de $5 \mathrm{mg} / \mathrm{ml}$, volume de $0,1 \mathrm{~mL} / 100 \mathrm{~g}$ de peso corporal por via subcutânea e extrato na concentração de $500 \mathrm{mg} / \mathrm{ml}$ no volume de $1 \mathrm{ml} / 100 \mathrm{~g}$ de peso corporal por gavagem.

Extrato $1000 \mathrm{mg} / 100 \mathrm{~g}$ + Testosterona: os animais receberam solução de testosterona na concentração de 5 $\mathrm{mg} / \mathrm{ml}$, volume de $0,1 \mathrm{ml} / 100 \mathrm{~g}$ de peso corporal por via subcutânea e extrato na concentração de $1000 \mathrm{mg} / \mathrm{mL}$ no volume de $1 \mathrm{ml} / 100 \mathrm{~g}$ de peso corporal por gavagem.

\section{Exame dos órgãos:}

Após 7 dias de tratamento, os ratos foram sacrificados por sobredose anestésica, os mesmos, foram previamente anestesiados utilizando-se a associação anestésica de cetamina (40 a $90 \mathrm{mg} / \mathrm{Kg}$ ) e xilazina $(3-5 \mathrm{mg} / \mathrm{Kg}$ ), método este em conformidade com a resolução no 1000 de 11/05/2012 do Conselho Federal de Medicina
Veterinária - CFMV. Para a avaliação dos órgãos, estes foram, então, removidas e pesados os testículos, a próstata, vesículas seminais e glândulas adrenais, bem como fígado, rins e coração onde realizou-se ressecções para processamento e análise histopatológica de acordo com Bacha e Wood (1990).

\section{Análise Estatística}

Em seguida, os dados recolhidos foram submetidos a análise estatística. A média de peso das glândulas acessórias de qualquer dos grupos tratados apenas com extrato tenha sido significativamente superior à média do grupo controle negativo foi considerado que houve atividade androgênica. Caso a média do grupo controle positivo tenha sido inferior a qualquer um dos grupos tratados com extrato+testosterona, foi considerado que houve atividade antiandrogênica. Os resultados paramétricos foram submetidos à análise de variância e pós teste de Bonferroni.

\section{RESULTADOS E DISCUSSÃO}

A observação sobre o ganho de peso corporal é importante, pois a redução e o aumento significativos podem refletir uma variedade de respostas, incluindo: anorexia induzida pelo tratamento ou mesmo uma possível toxicidade sistêmica (MULLER et al., 2009).

Analisando os resultados, do experimento, com o extrato do fruto de Buchenavia sp, observou-se que não houve diferença estatística significativa em relação à evolução ponderal dos animais, bem como, peso da adrenal e peso da próstata (Figura - 1), denotando que o extrato de Buchenavia sp, nas doses aplicadas não interferiu no ganho de peso dos animais.

Resultado diferente, foi observado por Ferreira et al., (2016), no 
estudo da avaliação das atividades estrogênica e antiestrogênica e da influência do extrato etanólico da casca de Buchenavia sp., sobre o ciclo estral de ratas, onde observou-se a redução do ganho de peso dos grupos tratados com o extrato durante o período de administração dos mesmos nas diferentes concentrações., resultado atribuído a possível efeito toxico subcrônico de princípios ativos presentes na casca de Buchenavia sp, ainda desconhecidos. A partir dessa observação, pode-se sugerir que tais compostos devem encontrar-se em menor quantidade ou inexistirem no fruto.

Alterações no ganho de peso, quando ocorrem, podem ser atribuídas a constituintes presentes no extrato, ou, ao aumento/redução do consumo de água e ração, que podem ser induzidas por possíveis alterações na palatabilidade, podendo ou não, serem atribuídos a efeitos tóxicos diretos, conforme relataram Bezerra; Carvalho; Chaves, (2009) em seus experimentos com o extrato de Parkia platycephala Benth e Ferreira et al., (2016) com o extrato da casca de Buchenavia sp.

A análise histopatológica de rins, coração e fígado não revelou sinais de alterações degenerativas, necróticas ou inflamatórias que pudessem ser atribuídas a um possível efeito sistêmico do extrato do fruto de Buchenavia sp. Da mesma forma, sinais visíveis de toxicidade nos ratos, como: anorexia, tremores, diarréia, piloereção ou convulsões, foram ausentes.

Ensaios toxicológicos de curta ou longa duração com animais de experimentação podem indicar 0 potencial desregulador endócrino de substancias químicas quando registram efeitos adversos sobre órgãos reprodutivos e ou endócrinos, ou especificamente sobre os processos de reprodução e desenvolvimento. (MARTINEZ, 2012).
O teste de Hershberger, um ensaio in vivo de curta duração utilizado na detecção de substâncias androgênicas ou antiandrogênicas e é baseado no crescimento de tecidos andrógenos dependentes (próstata e vesícula seminal) (androgenicidade) ou no bloqueio da ação trófica da testosterona (antiandrogenicidade) sobre esses tecidos (KITA, 2004). A sensibilidade do teste, está no uso de animais com mínima produção endógena de andrógeno e mínima variabilidade do peso inicial dos tecidos e órgãos alvo. Como os níveis de andrógenos circulantes são muito baixos, o eixo hipotálamo-hipófisegonadal não e capaz de compensar o feedback sobre os mecanismos internos, e a habilidade de resposta dos tecidos é maximizada (OECD, 2010; EDSP/USEPA, 2011).

A aferição do peso relativo dos órgãos sexuais e glândulas acessórias podem fornecer indícios da função destes órgão, bem como, da atuação da substância testada sobre o organismo.

A média de peso da vesícula seminal do grupo tratado com $1000 \mathrm{mg} / \mathrm{kg}$ (b) foi diferente do grupo de $250 \mathrm{mg} / \mathrm{Kg}$ (b) e os grupos tratados com testosterona foram diferentes de todos não tratados (a) (Figura - 2). A média de peso do testículo do grupo tratado com extrato $250 \mathrm{mg} / \mathrm{kg}$ foi significativamente superior à média do grupo controle negativo podendo denotar uma atividade androgênica (Figura - 3). Porém esse resultado de forma isolada não constitui sinal significativo de atividade androgênica. Estudos de Ashby et al. (2004) também revelam dados conflitantes acerca dos testículos, como exemplo, a alta variabilidade de peso internanimal, sugerindo que o testículo não é um bom órgão para a identificação de substâncias desreguladoras endócrinas no teste de animais recém desmamados e 
estimulados por Testosterona

(TINWELL et al., 2007).

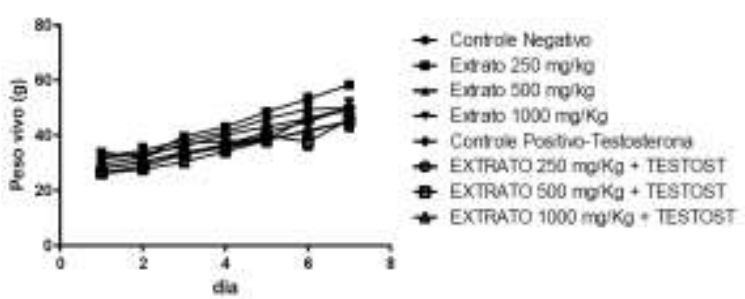

Figura 1 - Resultado da Evolução Ponderal (ANOVA e pós teste de Bonferroni).

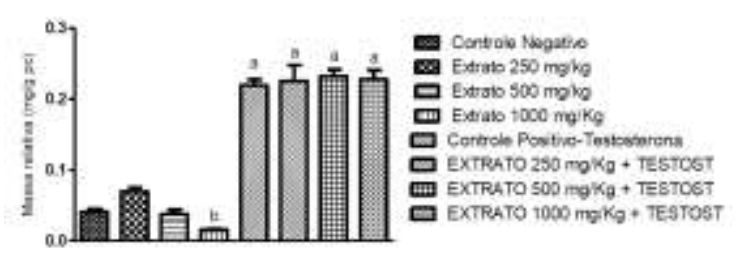

Figura 2 - Resultado da Massa relativa da vesícula seminal (ANOVA e pós teste de Bonferroni).

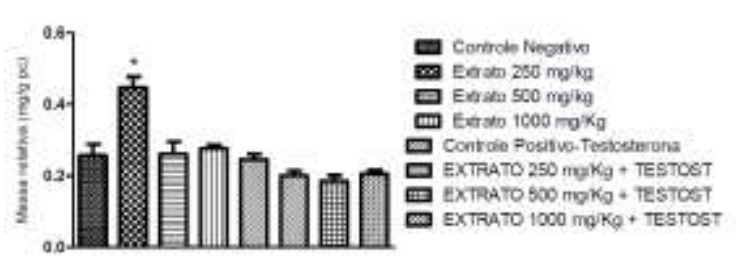

Figura 3 - Resultado da Massa relativa dos testículos (ANOVA e pós teste de Bonferroni).

Não foi verificada diferença significativa entre os pesos das adrenais e próstata entre os grupos tratados com as diferentes doses do Extrato $(250,500$ e $1000 \mathrm{mg} / \mathrm{kg}$ ) e os grupos controle (Negativo e Positivo), indicando falta de atividade androgênica e antiestrogênica por não inibir nem potencializar o efeito do andrógeno nos órgãos estudados (figuras - 4 e 5).

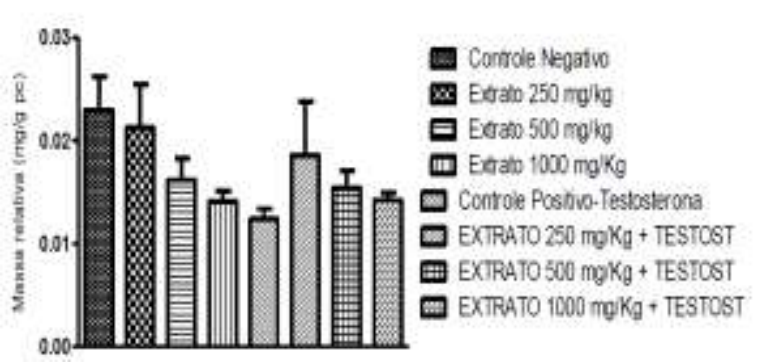

Figura 4 - Resultado da Massa relativa da Adrenal (ANOVA e pós teste de Bonferroni).

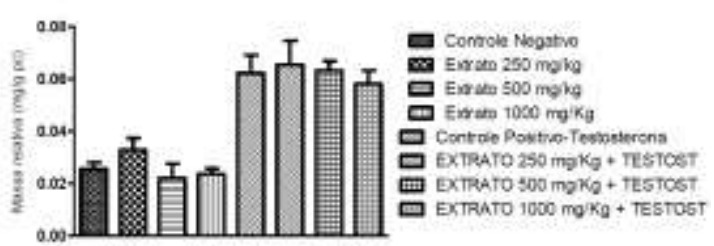

Figura 5 - Resultado da Massa relativa da próstata (ANOVA e pós teste de Bonferroni).

Conforme os resultados observados no experimento, sugere-se, que novos estudos devam ser realizados.

\section{CONCLUSÃO}

O extrato aquoso do fruto da Buchenavia sp. não apresentou atividade androgênica ou antiandrogênica em ratos impúberes segundo o protocolo de curta duração (Teste de Hershberger), bem como, não influenciou no ganho de peso dos animais e não levou a observação de alterações degenerativas, inflamatórias ou necróticas dos órgãos analisados e não desencadeou toxicidade sistêmica.

\section{NOTAS INFORMATIVAS}

O protocolo experimental foi submetido e aprovado pelo Comitê de Ética em Experimentação Animal da UFPI com Parecer ํo 041/12.

\section{REFERÊNCIAS}


ABOU-DONIA, M. B. Physiological effects and metabolism of gossypol. Residue Revie, v. 61, p.125, 1976.

BRANDOLT, T. D. D.; RODRIGUES, C. C., FERRÃO, S. M. N., SILVA, G. M. B. Efeito do extrato de Plectranthus barbatus (Andr.) Benth no desempenho reprodutivo de Rattus novergicus (Berkenhout, 1769), Biotemas, 20 (2): 49-58, junho de 2007.

COSTA, A.M.D. Plantas toxicas de interesse agropecuario nas microrregioes de Araguaina e Bico do Papagaio, Norte do Tocantins. 104f. Dissertação (Mestrado em Ciência Animal Tropical) -Universidade Federal do Tocantins, Tocantins, 2009.

FERREIRA, M.D.S.; BATISTA, M.C.S.; SILVA, S.M.M.S. Estudo de toxicidade de planta de interesse pecuário. Estudo de toxicidade sistêmica e reprodutiva do extrato etanólico da casca de Buchenavia sp. em ratos. Editora Novas Edições Acadêmicas. 60p. 2016.

KUROYANAGI M., ARAKAWA T., HIRAYAMA Y., HAYASHI T., Journal of Natural Products., 62, 1595-1599, 1999.

MARQUETE, N. F. DA S.; VALENTE, M. C. Flora da Reserva Ducke, Amazonas, Brasil: Combretaceae. Rodriguésia v.56, n.86, p.131-140, 2005.

MELLO, G. W. S.; OLIVEIRA, D. M.; CARVALHO, C. J. S.; PIRES, L. V.; COSTA, F. A. L. ; RIETCORREA, F. ; SILVA, S. M. M. S. . Plantas tóxicas para ruminantes e equídeos no Norte Piauiense. Pesquisa Veterinária Brasileira, v. 30, p. 1-9, 2010.

POTT, A.; POTT, V. J. Plantas comestíveis e medicinais da Nhecolândia, Pantanal. EMBRAPACPAP, Pesquisa em andamento, Corumbá. v. 4, p.1-7. 1986.
POTT, A.; POTT, V.J.; SOUZA, T.W. Plantas daninhas de pastagem na região dos cerrados. EMBRAPA Gado de Corte. Campo Grande, MS. 336 p. 2006.

MARTINEZ, M. F., Ação de mistura de praguicidas no sistema reprodutor de ratos Lewis machos. Tese (doutorado) Universidade Estadual Paulista, Faculdade de Medicina de Botucatu. Botucatu-SP, 2012. 101p.

KITA, D. H., Efeitos do Pesticida Roudup sobre o sistema reprodutor de ratos wistar. Monografia (Ciências Biológicas). Universidade Federal do Paraná, Curitiba-PR, 2004. 43p.

TINWELL, H. FRIRY-SANTINI, C. ROUQUIE, D., BELLUCO, S., ELIES, L., PALLEN, C., BARS, R., Evaluation of the antiandrogenic effects of flutamide, DDE, and linuron in the weanling rat assay using organ weight, histopathological, and proteomic approaches. Toxicol Sci 100, 54-65, doi: (2007).10.1093/toxsci/kfm208.

BACHA, W.J.; WOOD, L.M. Colors atlas of veterinary histology. Philadelphia: Lea and Febiger, Philadelphia. 1990. 269p.

CFMV. Conselho Federal de Medicina Veterinária. Resolução $\mathrm{n}^{\circ} 1000$ de 11/05/2012.

MULLER, J.C.; GIULIANA G.K; BOTELHO, A.C. et al. Toxicidade reprodutiva da 302 Morinda citrifolia Linn. Journal Ethnopharmacology, v.12, p.229-233, 2009.

BEZERRA, R.D.S.; CARVALHO, A.A.; CHAVES, M.H. Fenóis totais e atividade 282 antioxidante de extratos das folhas de Parkia platycephala BENTH. In: $32^{\text {a }}$ Reunião Anual da 283 SBQ, 2009, Fortaleza. Anais...32 $2^{a}$ Reunião Anual da SBQ, 2009.

OECD (Organisation for Economic Cooperation and Development). Guidance Document on the Assessment of Chemicals for Endocrine Disruption 
Version 9 (with changes to V8 accepted, 17 November 2010). Disponivel em: http://www.oecd.org/dataoecd/63/8/4643 6593.pdf. Acesso em 10/jun/2013.

EDSP/USEPA Endocrine Disruptor Screening Program. (United States Environmental Protection Agency). Weight-of-Evidence: Evaluating Results of EDSP Tier 1 Screening to Identify the Need for Tier 2 Testing. Office of Chemical Safety and Pollution Prevention Washington DC 20460 September 14, 2011. p.1-47.

ASHBY, J., LEFEVRE, P.A., TINWELL, H., ODUM, J., OWENSB, W., Testosterone-stimulated weanlings as an alternative to castrated male rats in the Hershberger anti-androgen assay. Regulatory Toxicology and Pharmacology. 2004, 39:229-238. 